\title{
Synthesis and Fabrication of Graphene and Graphene Oxide: A Review
}

\author{
Adeniji Adetayo, Damilola Runsewe \\ Department of Chemistry and Biochemistry, Texas State University, San Marcos, TX, USA \\ Email: aea112@txstate.edu
}

How to cite this paper: Adetayo, A. and Runsewe, D. (2019) Synthesis and Fabrication of Graphene and Graphene Oxide: A Review. Open Journal of Composite Materials, 9, 207-229.

https://doi.org/10.4236/ojcm.2019.92012

Received: April 4, 2019

Accepted: April 26, 2019

Published: April 29, 2019

Copyright ( 2019 by author(s) and Scientific Research Publishing Inc. This work is licensed under the Creative Commons Attribution International License (CC BY 4.0).

http://creativecommons.org/licenses/by/4.0/

(c) (i) Open Access

\begin{abstract}
The field of nanotechnology has advanced following the discovery of a two-dimensional material of $\mathrm{sp}^{2}$ hybridized carbon atoms, graphene in 2004 by Geim and Novoselov. Graphene has received so much attention due to its exceptional electronic, thermal, mechanical, and optical properties in addition to its large surface area and single-atom thickness. This has led to the discovery of several techniques to obtain graphene such as chemical exfoliation, chemical vapor deposition (CVD), chemical synthesis etc. However, these techniques are majorly challenged with developing graphene with fewer defects and in large scale; thus, there is an increasing need to produce graphene in large quantities with high quality. Several studies have been carried out to find routes to producing high-quality graphene. This paper focuses majorly on the synthesis and fabrication methods of producing graphene and its derivative, graphene oxide. Characterization techniques to identify graphene such as optical microscopy, scanning electron microscopy (SEM), Raman spectroscopy, scanning probe microscopy (SPM) used to determine number of layers, quality, atomic structures, and defects in graphene is also briefly discussed. This article also covers a short description of graphene applications in transparent electrodes, composites and energy storage devices.
\end{abstract}

\section{Keywords}

CVD, Exfoliation, Graphene, Graphene Oxide, Synthesis

\section{Introduction}

The field of nanotechnology has blossomed following several studies on carbon. Carbon exists in three-dimensional (3D) forms (regarded as allotropes) as diamond and graphite. Evidence of the 3D graphitic form of carbon dates as far back to 1500s [1] [2]. This brought about its use as a writing material in the 
1900s as the pencil industry was developed [3]. Other carbon allotropes, such as zero-dimensional (0D) fullerene [1] and one-dimensional (1D) carbon nanotubes [2] were discovered in the 1980s and 1990s (Figure 1). However, there remained an argument on the existence of two-dimensional (2D) allotrope of carbon until 2004, when a publication by Andre Geim and Konstantin Novoselov documented a successful isolation of a single layer of graphite (graphene) on a sticky tape by micromechanical cleavage (scotch tape method) of highly ordered pyrolytic graphite (HOPG) [4].

Graphene is a two dimensional (2D) single layer structure of covalently bonded $\mathrm{sp}^{2}$-hybridized carbon atoms arranged in a hexagonal honeycomb network. It is a single-atom thick allotrope of carbon which serves as the basic structural unit for other carbon allotropic forms: 1) 0D fullerenes formed by wrapping up graphene sheet to form a sphere (Bucky ball), 2) 1D carbon nanotube (CNT) formed by rolling of a graphene sheet to form a cylindrical structure, and 3) 3D graphite formed by stacking several layers of individual graphene sheet held together by van der Waals bonds as shown in Figure 1 [5].

Single, double, and triple graphitic layers are commonly known as monolayer, bilayer, and trilayer graphene's respectively. Graphene layers exceeding 5 and up to 30 aregenerally called multilayer graphene/thick graphene [6]. In graphene, the carbon-carbon bond distance is about $0.142 \mathrm{~nm}(1.42 \AA)$ with the layer height (thickness) of about $0.33 \mathrm{~nm}(3.3 \AA$ ) (Figure 2) [3].

Graphene shows exceptional properties including a large theoretical specific surface area $\left(2630 \mathrm{~m}^{2} \mathrm{~g}^{-1}\right)$ [7], high intrinsic mobility $\left(200,000 \mathrm{~cm}^{2} \mathrm{~V}^{-1} \mathrm{~s}^{-1}\right)$ [8] [9], high Young's modulus $(\sim 1.0 \mathrm{TPa})[10]$, and thermal conductivity $\left(\sim 5000 \mathrm{Wm}^{-1} \mathrm{~K}^{-1}\right)$ [11]. It also has good optical transmittance ( 97.7\%), good electrical conductivity, and ability to withstand current density of $108 \mathrm{~A} / \mathrm{cm}^{2}$ [12]. Graphene is also known to be a zero-bandgap semiconductor; therefore, the band gap can be tuned through simple physicochemical processes [13].

Owing to its exciting properties, study on graphene and its derivatives in the field of materials science and condensed-matter physics has generated immense attention over the past few years with various applications including membranes [14] [15], nanoelectronics [16] [17] [18], Li-ion batteries [19], electrodes [20] [21] [22], supercapacitors [23], sensors [24], drug delivery [25], etc.

Graphene produced through micromechanical cleavage of graphite was pure with high quality, although it was time consuming and incapable of mass scale production. Recently, several other techniques have been reported for the fabrication and synthesis of graphene, such as epitaxial growth by chemical vapor deposition on copper $(\mathrm{Cu})$ substrate [26] [27], epitaxial growth by thermal deposition of $\mathrm{Si}$ atom from $\mathrm{SiC}$ surface [28], colloidal suspension from graphite oxide [29], and many others.

\section{Synthesis of Graphene}

The process of fabricating or extracting graphene based on desired size and quality is regarded as synthesis of graphene. So far, numerous approaches to 
synthesis of graphene and graphene derivatives have been established. Mechanical cleaving (exfoliation) [4], chemical synthesis [30], chemical exfoliation [31] [32], epitaxial growth [33], and thermal chemical vapor deposition (CVD) [34] methods have been extensively studied. Other methods including electrochemical exfoliation [35], microwave synthesis [36], and unzipping of CNT [37] [38] [39] have been reported. Generally, graphene synthesis methods for large scale production, including single layer graphene (SLG), bilayer graphene, and few layer graphene (FLG) can be broadly classified into two types: 1) top-down process, and 2) bottom-up process. The classification of each technique is shown in the flow chart in Figure 3.

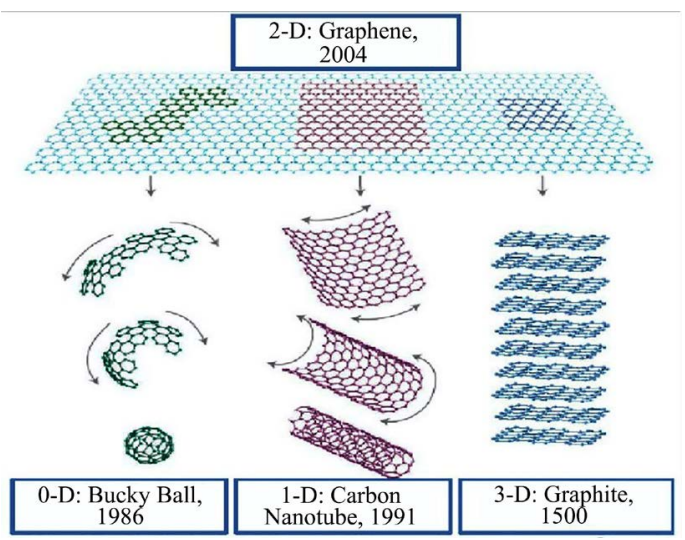

Figure 1. The 2D hexagonal nanosheets of graphene as a building block of other forms. An illustration of different allotropes of carbon arising from a graphene sheet [5].

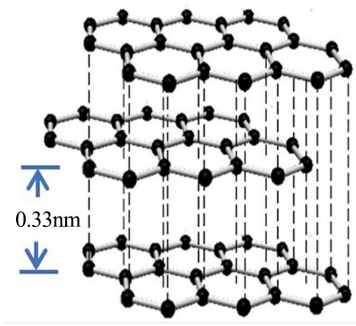

(a)

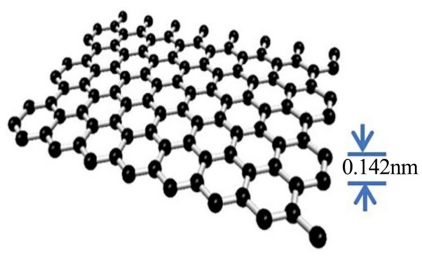

(b)

Figure 2. Schematic diagram of (a) Graphite and (b) Single layer of graphene from graphite.

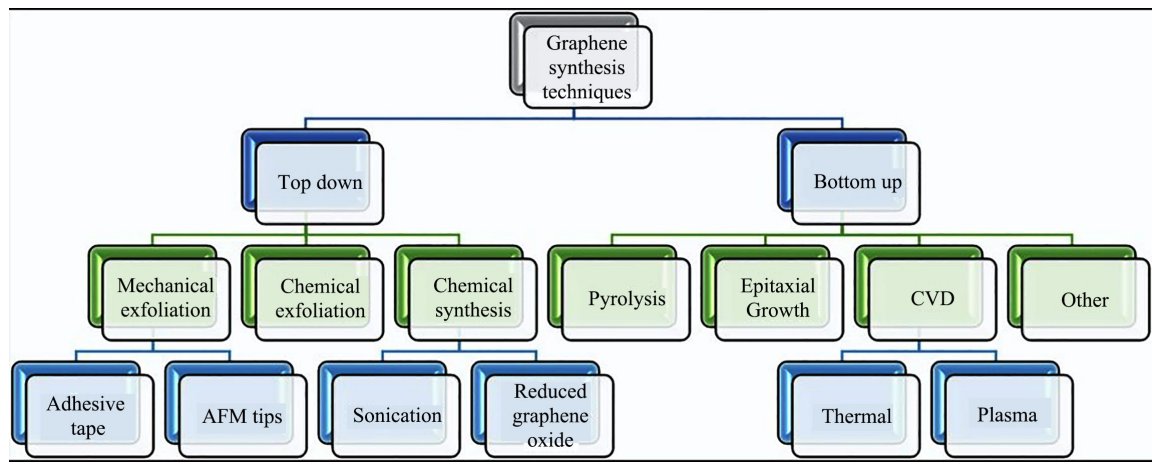

Figure 3. Graphene synthesis processes flow chart [47]. 


\subsection{Top-Down Process}

In the top-down process, graphene sheets are produced by exfoliation or separation of highly ordered pyrolytic graphite (HOPG) or its derivative, graphene oxide (GO).

\subsubsection{Mechanical Exfoliation}

Mechanical exfoliation is the first established method of extraction of graphene flakes on a substrate [4]. In nanotechnology, it is a top-down method of graphene synthesis, by which a stress (longitudinal or transverse) is applied to layered graphite surface using a simple adhesive tape (scotch tape) or AFM tip. Graphite structure is composed of several single-atomic layers of graphene stacked and held together by weak van der Waals forces. Between each layer is an interlayer distance of $3.3 \AA(0.33 \mathrm{~nm})$ and interbond energy of $2 \mathrm{eV} / \mathrm{nm}^{2}$. Single layer graphene (SLG) to few layer graphene (FLG) can be produced through mechanical cleaving by slicing down the layers from graphitic materials such as HOPG, single-crystal graphite or natural graphite [40] [41]. This method re-

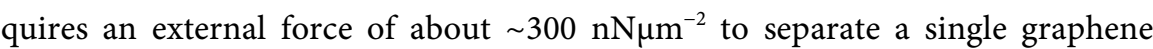
layer from graphite [42]. Mechanical exfoliation can be achieved using several agents including scotch tape [4], electric field [43], and ultrasonication [44]. Prior to the first production of a single layer graphene by Novoselov et al., Ruoff et al. [41] first produced thin multilayered graphite with about $200 \mathrm{~nm}$ thickness by mechanical exfoliation using AFM tip (Figure 4(a)). Figure 4(b) shows the micro-graph of fabricated thin multilayered graphite consisting of 500-600 layers of monolayer graphene.

Novoselov et al. [4] utilized adhesive tape to produce single graphene layer (thickness $<10 \mathrm{~nm}$ ) by exfoliation from $1 \mathrm{~mm}$ thick HOPG mesa. This involved compressing dry etched graphite mesa (by oxygen plasma) against a $1 \mathrm{~mm}$ thick wet photoresist layer over a glass substrate. Baking was done to attach the HOPG mesa to the layer of photoresist and exfoliation of the graphite flakes was achieved by using the scotch tape. Dispersed graphite flakes in acetone was transferred onto a cleaned $\mathrm{SiO}_{2} / \mathrm{Si}$ substrate. Figure 4(c) shows optical micro-graph of multilayer graphene flakes produced via mechanical exfoliation on top of $\mathrm{SiO}_{2} / \mathrm{Si}$ substrate while Figure 4(d) shows the identification of single graphene flakes with different number of layers.

The problem with the exfoliation process is scalability and reproducibility. Though it produces high quality graphene layers, there is still a need for further improvement to produce large-scale, high quality, and defect-free graphene for use in nanotechnology.

\subsubsection{Chemical Exfoliation}

Chemical exfoliation is another route to obtaining monolayer graphene. This method involves production of suspension which changesgraphite to form graphene through the formation of graphene-intercalated compounds (GICs). This involves the introduction of alkali metals into a graphite solution to increase the 
interlayer spacing, thereby reducing the van der Waals forces between the layers and forming GICs which are then dispersed in a liquid medium through sonication to form single-layer graphene [45]. Alkali metals are the only choice of materials as they easily form GICs on reaction with graphite due to the difference in ionization potential between graphite and alkali metals. Chemical exfoliation methodology was used by Viculis et al. to obtain graphene nanoplatelets (GNP) using potassium alkali metal [46]. Potassium graphite $\left(\mathrm{KC}_{8}\right)$ intercalated compound was formed when potassium reacted with graphite at $200^{\circ} \mathrm{C}$ under inert atmosphere. Dispersion of the GIC in aqueous ethanol $\left(\mathrm{CH}_{3} \mathrm{CH}_{2} \mathrm{OH}\right)$ resulted in an exothermic reaction as shown in (1) and produced GNP.

$$
\mathrm{KC}_{8}+\mathrm{CH}_{3} \mathrm{CH}_{2} \mathrm{OH} \rightarrow 8 \mathrm{C}+\mathrm{KOCH}_{2} \mathrm{CH}_{3}+\frac{1}{2} \mathrm{H}_{2}
$$

Potassium ions dissolve into the ethanol solution forming potassium ethoxide $\left(\mathrm{KOCH}_{2} \mathrm{CH}_{3}\right)$ and hydrogen gas is formed to aid the separation of the layers of graphene. Precaution must be taken during this reaction as alkali metals vigorously react with water and alcohol, as such there is a need for an ice bath to dissipate heat during reaction. The main advantage of alkali metals, such as potassium, is their relatively small atomic radius which is smaller than the interlayer spacing in graphite and hence fits the interlayer spacing easily as shown in Figure 5(a).

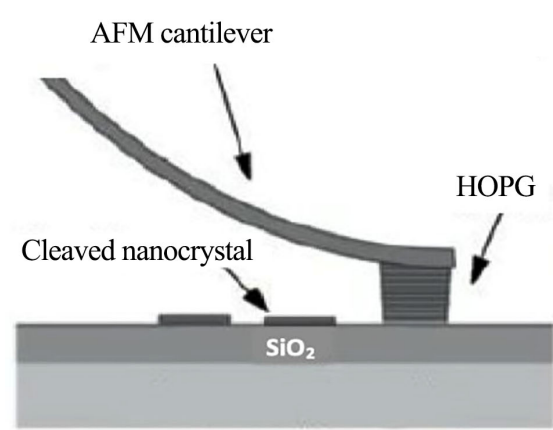

(a)

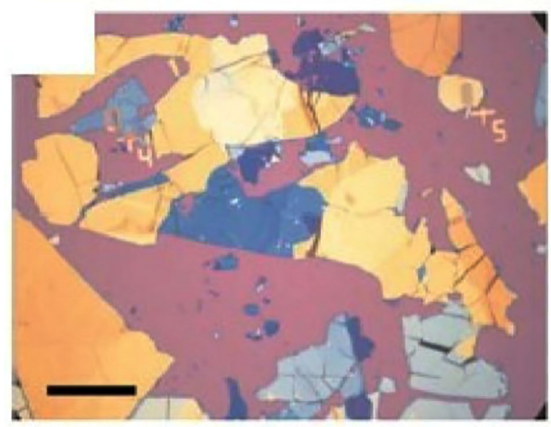

(c)

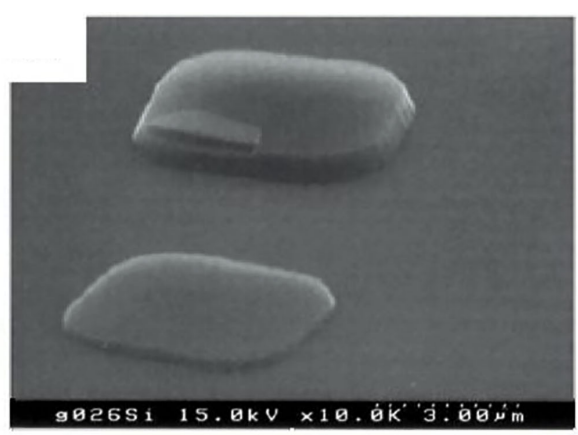

(b)

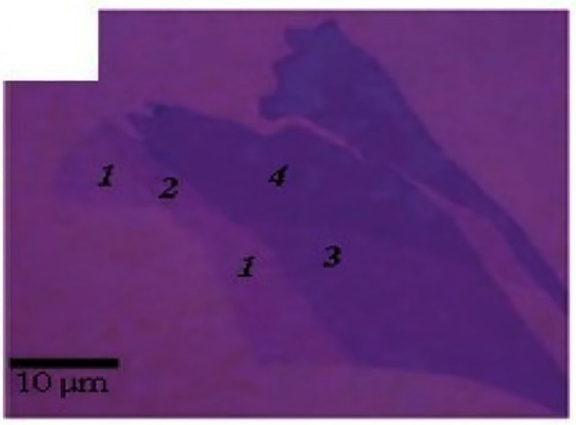

(d)

Figure 4. (a) Mechanical exfoliation process by using AFM; (b) SEM micrograph of mechanically exfoliated thin graphite layers from HOPG using AFM; (c) Optical micro-graph of few graphene flakes produced by the scotch tape method (scale bar 50 $\mu \mathrm{m}) ;(\mathrm{d})$ Graphene layer of various thickness on $\mathrm{SiO}_{2} / \mathrm{Si}$ substrate. 
(a)

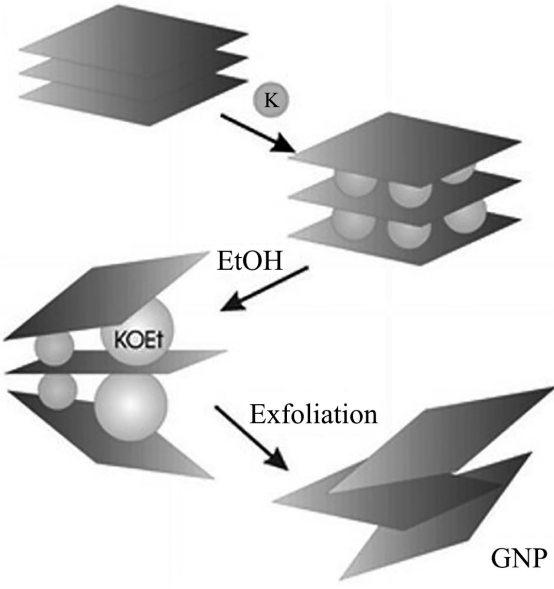

(c)

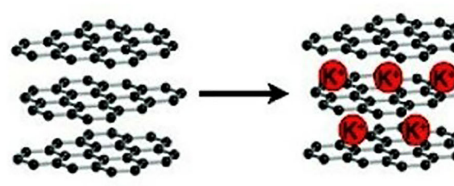

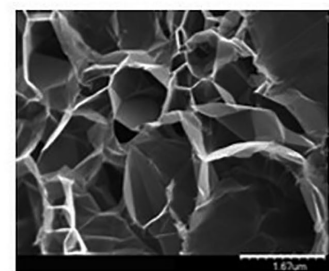
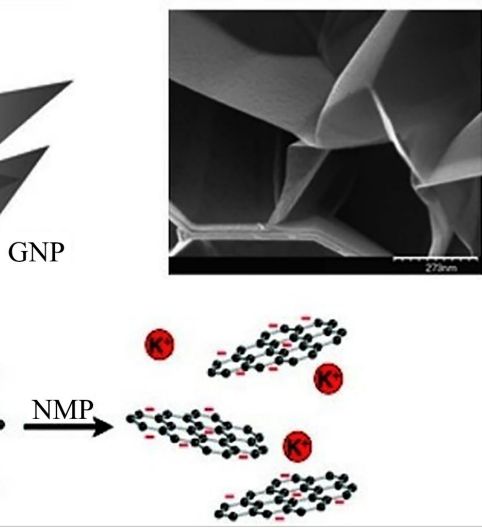

Figure 5. (a) Schematic showing the intercalation of potassium between layers during chemical exfoliation process [46]; (b) SEM micrographs of chemically exfoliated graphite nanoplatelets [46]; (c) Schematic illustrating the production of negatively charged graphene sheets [48].

Figure 5(b) shows SEM micrographs of the chemically exfoliated GNP with $\sim 10 \mathrm{~nm}$ thickness and $\sim 30$ layers. Viculis et al. also carried out exfoliation via GIC formation using an alkali metal such as Cesium (Cs) and $\mathrm{NaK}_{2}$ (sodium-potassium) alloy [32]. Work by Vallés et al. [48] utilized ternary potassium salt $\mathrm{K}(\mathrm{THF})_{\mathrm{x}} \mathrm{C}_{24}$ tetrahydrofuran (THF) as the alkali metal to prepare potassium-intercalated GICs which was dispersed in N-methyl pyrrolidone (NMP) to yield a stable dispersion of negatively charged SLG as shown in Figure 5(c).

One major challenge in this work was the reassembly of produced graphene back into graphite. Later studies have incorporated surfactants in the solvent used and utilized immiscible liquids such as heptane and water [48] [49]. Other studies have utilized ferric chloride, supercritical carbon dioxide, and nitromethane as the intercalation chemicals [50] [51] [52].

Graphene synthesis through chemical exfoliation is important and unique as it can produce a large amount of graphene at a low temperature. It is also scalable and can be extended to a wide range of functionalized graphene production.

\subsubsection{Chemical Synthesis}

Chemical reduction of graphite oxide (GO) is one of the conventional ways of preparing graphene in large quantities. The three routes available for GO synthesis; the Brodie method [5], Staudenmaier method [53], and Hummers method [54] consist of oxidation of graphite through strong acids and oxidants such as concentrated sulfuric acid $\left(\mathrm{H}_{2} \mathrm{SO}_{4}\right)$, nitric acid, and potassium permanganate. Oxidation degree can be varied by the stoichiometry, reaction conditions 
(pressure, temperature, etc.), and the graphite type (HOPG, pure graphite, etc.). The works of Brodie et al. [5] in 1859 first demonstrated the synthesis of GO by adding potassium chlorate $\left(\mathrm{KClO}_{3}\right)$ to a graphite slurry in the presence of fuming nitric acid $\left(\mathrm{HNO}_{3}\right)$. However, the process was time consuming, involved several steps, and hazardous. This brought about a modification to the process by Staudenmaier et al. in 1898 [53] with the inclusion of concentrated $\mathrm{H}_{2} \mathrm{SO}_{4}$ to the process and resulted in the production of highly oxidized GO in a single step process. A popular method used today was developed in 1958 by Hummers et al. [54]. This involves the oxidation of graphite by mixing the graphite slurry in sodium nitrite $\left(\mathrm{NaNO}_{3}\right)$, concentrated $\mathrm{H}_{2} \mathrm{SO}_{4}$, and potassium permanganate $\left(\mathrm{KMnO}_{4}\right)$ without the use of $\mathrm{HNO}_{3}$. Figure 6 shows a schematic diagram of GO synthesis from graphite method using the three methods explained.

When graphite turns to GO, the interlayer spacing is increased to between two to three times depending on the oxidation time. In the case of pristine graphite, interlayer spacing is increased from about $3.34 \AA$ to $5.62 \AA$ after an hour of oxidation, and then further expanded to about $7.35 \AA$ upon prolonged oxidation of 24 hours [5]. Upon ultrasonication in a DMF/water (9:1) (dimethyl formamide), GO interlayer distance is further expanded, forming individual layer suspensions. With hydrazine hydrate treatment, GO reduces back to graphene or reduced graphene oxide (RGO). The chemical reduction process is done using dimethyl hydrazine or hydrazine in the presence of a surfactant or polymer to produce homogenous colloidal graphene suspensions [55]. Figure 7 shows the process for chemical synthesis of graphene from graphite. Reduction of GO has also been performed using sodium borohydride $\left(\mathrm{NaBH}_{4}\right)$ [56], hydroxylamine [57], hydroquinone [58], ascorbic acid [59], etc. as reducing agents.

The use of toxic chemicals such as $\mathrm{HNO}_{3}$ and $\mathrm{KClO}_{3}$ has prompted researchers to develop new methods to graphene oxide synthesis [60] [61] [62]. However, the Hummer's method has been found to be quicker, safer, and more efficient method for graphene oxide synthesis used widely today with some modifications. Hummer's method was modified and further improved by Marcano et al. with the use of a larger amount of $\mathrm{KMnO}_{4}$, exclusion of $\mathrm{NaNO}_{3}$, and a 9:1 reaction mixture of $\mathrm{H}_{2} \mathrm{SO}_{4} / \mathrm{H}_{3} \mathrm{PO}_{4}$ [61]. Compared to the Hummer's method, this improved method shows higher oxidation efficiency and production of better hydrophilic oxidized graphene product [61].

Various reports on the production of graphene by graphene oxide reduction exists. Some of the methods involve thermal reduction [63] [64] [65], electrochemical reduction [66] [67], photochemical reduction [68], hydrothermal reduction [69], microwave assisted reduction [70], and chemical reduction using reducing agents [71].

Paredes et al. [29] produced graphene nanosheet derived from graphene oxide using the Hummer's method with the reduced and unreduced aqueous dispersion drop casted onto freshly cleaved HOPG substrate. It was reported that the chemically reduced graphene oxide nanosheets were hardly distinguishable from 
their counterparts in the topographic AFM images. However, they could be distinguished by their phase contrast with the unreduced graphene oxide showing a phase difference on the HOPG substrate while the RGO showed little phase contrast with the HOPG substrate (due to little defects). The thickness of the chemically reduced graphene oxide nanosheet was reported as $\sim 1 \mathrm{~nm}$ using tapping mode AFM as shown in Figure 8. It was concluded that the chemically reduced graphene oxide still contained some oxygen functional groups [29].

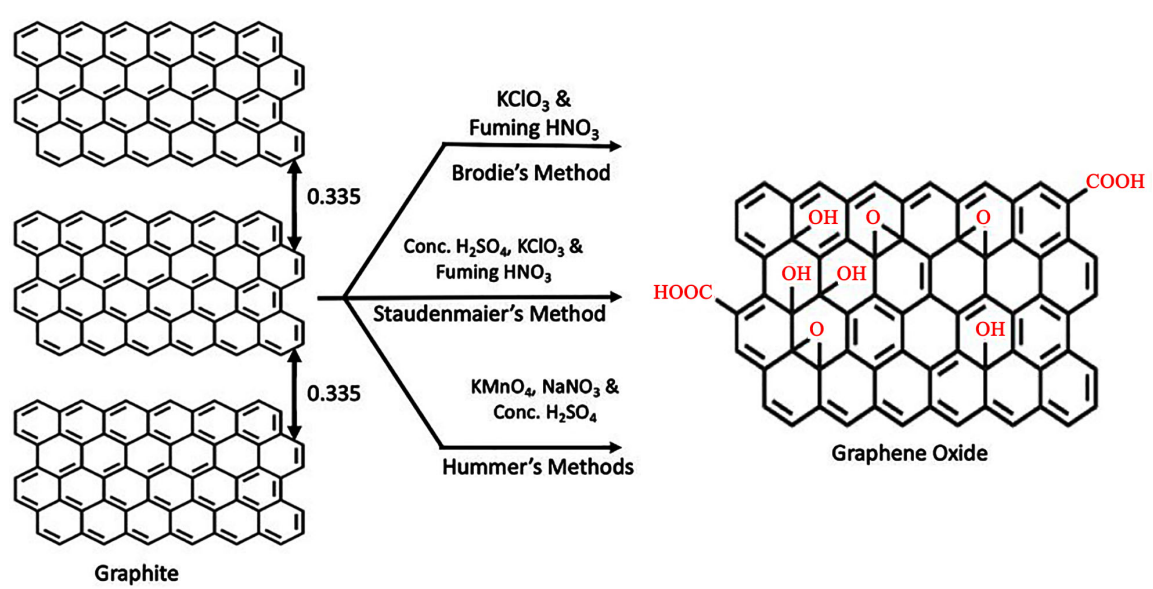

Figure 6. Schematic illustration of graphene oxide synthesis by chemical oxidation using Brodie's [5], Staudenmaier's [53], and Hummer's methods [54].

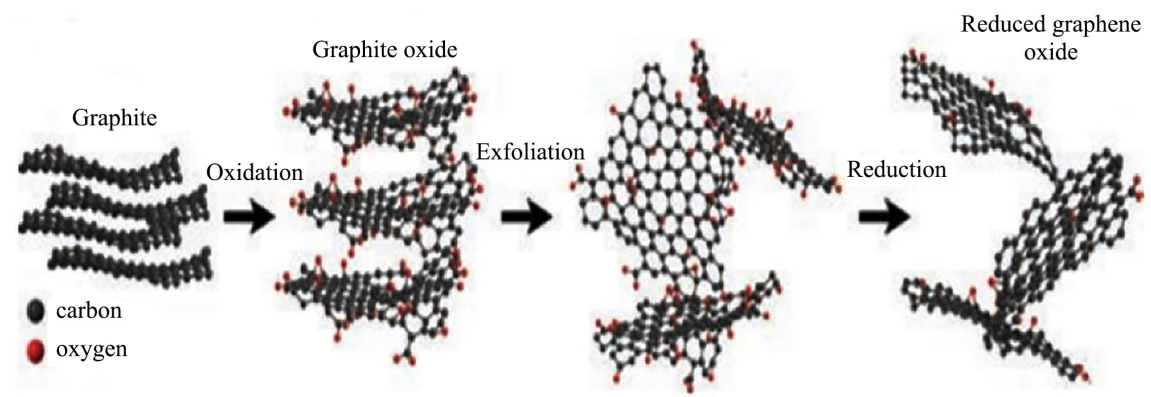

Figure 7. Synthesis route of graphene from graphite [72].

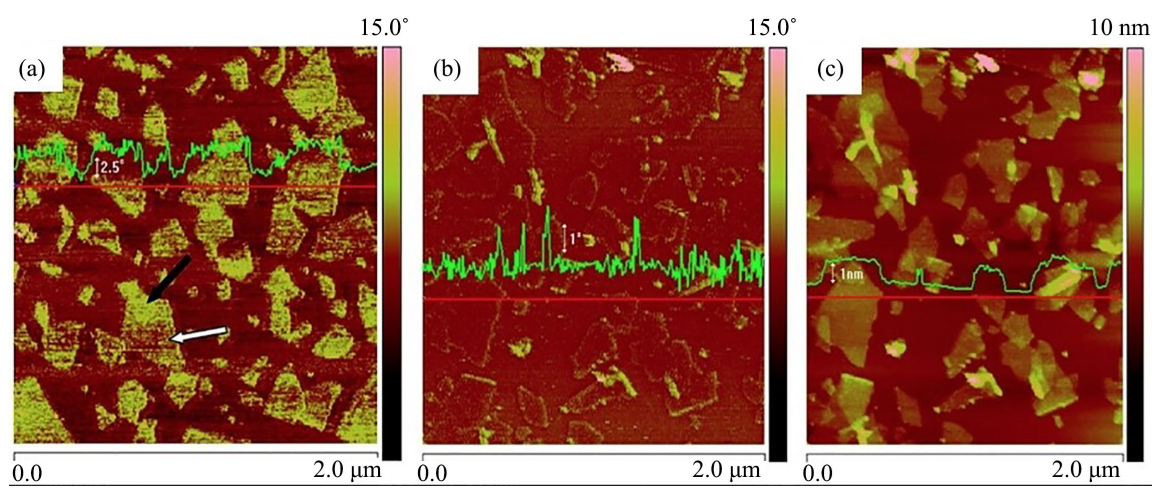

Figure 8. Tapping mode atomic force micrographs: (a) Phase image of unreduced graphene oxide nanosheet; (b) Phase image of chemically reduced graphene oxide nanosheet; (c) Height of chemically reduced graphene oxide nanosheet [29]. 
The chemical reduction method is the most useful method as it removes most of the functional groups present in the intermediate graphene oxide with the structure of the graphene surface restored after reduction. However, the produced graphene contains some defects due to the presence of remaining oxygen functional groups (such as $-\mathrm{OH}$ and $-\mathrm{COOH}$ ) that causes some disorder in the graphene electronic structure. This results in reduced electrical conductivity of produced graphene as compared to that of pristine graphene (defect-free). These remaining functional groups on graphene and RGO can be used to tune their electrical and chemical properties for different applications.

\subsection{Bottom-up Process}

In the bottom-up process, graphene sheets are produced by building up nanoscale material via atomic or molecular arrangement of carbon.

\subsubsection{Pyrolysis of Graphene}

This involves the solvothermal synthesis of graphene with the use of a solvent interacting with precursor [47]. This reaction is performed in a closed vessel under high pressure with a 1:1 molar ratio of ethanol and sodium. Using sonication, graphene sheets can be smoothly detached by pyrolysis of sodium ethoxide. The produced graphene sheets were determined to have dimensions up to 10 $\mu \mathrm{m}$. Using Raman spectroscopy and transmission electron microscopy (TEM), the graphene sheets were characterized to determine the crystalline structure, number of layers, band structure, and the graphitic nature [73]. Raman spectra showed a broad D-band (defect) and G-band with the intensity ratio of $\sim 1.16$ $\left(\mathrm{I}_{\mathrm{G}} / \mathrm{I}_{\mathrm{D}}\right)$, representative of single layer defective graphene. Though this process was less expensive, easy, and required low temperature, the presence of many defects reduced the graphene quality. This method of graphene production has not been widely explored.

\subsubsection{Epitaxial Growth of Graphene on SiC Surface}

Epitaxial thermal synthesis of graphene on the surface of single-crystalline silicon carbide $(\mathrm{SiC})$ is one of the well-known synthesis techniques. The term "epitaxy" is a method that allows the deposition of a single-crystalline film (epitaxial film) on a single-crystal substrate. When an epitaxial film is of the same material as the substrate, it is known as homoepitaxial layer, and if the epitaxial film and the substrate have different material, then an heteroepitaxial film is formed. Epitaxial growth on $\mathrm{SiC}$ forms an heteroepitaxial layer of single-layer graphite or graphene. In 1975, Bommel et al. [74] first reported heat treatment between $1000^{\circ} \mathrm{C}$ and $1500^{\circ} \mathrm{C}$ under ultrahigh pressure produced graphite on both polar planes of SiC. Synthesis by de Heer et al. in 2004 [75] produced ultrathin (few layers between 1 to 3 monoatomic graphene layers) graphitic layers on Si-terminated (0001) face of single-crystal $6 \mathrm{H}-\mathrm{SiC}$. Using the same thermal decomposition method, they fabricated 1 to 2 layers of epitaxial graphene on the (0001) face of $6 \mathrm{H}-\mathrm{SiC}$ [76]. Synthesized epitaxial graphene on $\mathrm{SiC}$ although had high quality, 
they could not be transferred to other substrates.

In 2012, Juang et al. [77] reported a breakthrough with the growth of epitaxial graphene on $\mathrm{SiC}$ substrate coated with $\mathrm{Ni}$ catalyst thin film. This produced graphene which was easily transferable to other substrate for versatile applications [77]. Epitaxial growth of graphene on $\mathrm{SiC}$ is very promising due to its scalability, best electronic properties, and especially due to its high-quality graphene.

\subsubsection{Chemical Vapor Deposition (CVD)}

Thermal chemical vapor deposition process involves exposure of a substrate to thermally decomposed precursors in gaseous state resulting in the deposition of the product onto the surface of the substrate at a high temperature. In many cases, deposition at high temperature is not desired, plasma-assisted reaction and deposition have been utilized to reduce the temperature. This process will be explained later in this paper. Depending on the quality, type of precursor, desired thickness of product, and structure, several types of CVD processes can be utilized including thermal, plasma enhanced (PECVD), reactive, hot wall, cold wall, etc. In the hot wall process, the walls of the reactor are kept relatively constant all around the reactor while in the cold wall process, the walls never get heated. Thermal CVD and PECVD are the most commonly used types of chemical vapor deposition to produce graphene. Figure 9 demonstrates the schematic of a thermal and plasma-enhanced CVD process.

1) Thermal chemical vapor deposition of graphene

This process of graphene production involves flowing of precursor gases such as methane, hydrogen and argon in certain ratios into a quartz tube containing a substrate such as $\mathrm{Cu}$ at high temperatures in a furnace (Figure 9(a)). Over time, there is a deposition of graphene comprising of either single layer, bilayer or multilayer depending on preset conditions such as gas flow rate, reaction time, pressure, and temperature. Deposition of high-quality graphene using CVD process is usually done on various transition-metal substrate (their surface acts as catalyst) such as $\mathrm{Ni}$ [78], Pd [73], Ru [79], Ir [80], and $\mathrm{Cu}$ [34] with different hydrocarbons such as methane, benzene, acetylene, and ethylene [34]. On exposure of the transition-metal to hydrocarbon gas at high temperature, there is carbon saturation on the substrate and a thin film of carbon is formed on cooling.

In 1966 [81], $\mathrm{Ni}$ was exposed to methane at a temperature of $900^{\circ} \mathrm{C}$ to form thin graphite. Formation of FLG was observed on the evaporation of carbon from a graphite rod in 1971 [82]. In 1975, Lang et al. [42] demonstrated the deposition of monolayer graphitic structure on Pt using ethylene for the first time. Eizenberg et al. [83] later reported the formation of graphitic layer on $\mathrm{Ni}$ (111) over a long reaction time. There was over two decades interval in single graphitic layer deposition research due to inadequacy in finding applications of thin graphite films. However, the discovery of graphene in 2004 [4] with potential application in graphene-based electronics, there arose wide interest in this material. 


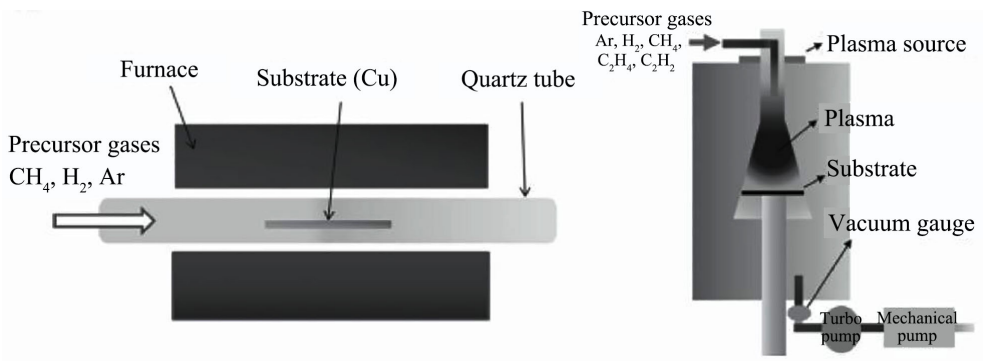

Figure 9. Schematic of (a) thermal CVD, and (b) plasma-enhanced CVD (PECVD) [5].

In 2006, the first attempt at synthesis of graphene on Ni foil via CVD method was found using camphor (terpenoid, a white transparent solid of chemical formula $\mathrm{C}_{10} \mathrm{H}_{16} \mathrm{O}$ ) as the precursor [84]. When viewed with the TEM, the product was found to have a hexagonal planar few-layer graphite-like structure consisting of almost $\sim 35$ layers of stacked SLG with interlayer spacing of $0.34 \mathrm{~nm}$. However, the first evidence of large-scale monolayer graphene using CVD growth was discovered by Obraztsov et al. [85] in 2007. The growth was achieved using precursors of methane and hydrogen under direct current (DC) discharge of $\sim 0.5 \mathrm{Acm}^{-2}$. The as-deposited graphene structure shown in Figure 10 shows the anomalous surface ridges which can be described as graphene folding lines [85]. The ridge formation in the graphene was due to the thermal expansion coefficient difference between graphene and Ni. Raman spectroscopy and scanning tunneling microscopy (STM) confirmed the presence of about $\sim 1-2 \mathrm{~nm}$ thick FLG [85].

Successively, other reports have demonstrated synthesis of single-to few-layer graphene on Ni substrate. In 2009, Reina et al. [34] utilized e-beam evaporated $\mathrm{Ni}$ on $\mathrm{SiO}_{2} / \mathrm{Si}$ substrate to grow graphene using diluted hydrocarbon gas. About 1 - 10 layers of graphene were observed using high resolution transmission electron microscopy (HRTEM) as shown in Figures 11(a)-(c). Raman spectroscopy was used to confirm the number of layers by the intensity ratio of the $\mathrm{G}^{\prime}(2 \mathrm{D})$ to $\mathrm{G}$ bands. The Raman signature were found around $\sim 1342 \mathrm{~cm}^{-1}, \sim 1581 \mathrm{~cm}^{-1}$, and $\sim 2677 \mathrm{~cm}^{-1}$ corresponding to the D, G, and G'(2D) bands of produced graphene respectively as shown in Figure 11(b) [34].

Graphene growth on $\mathrm{Cu}$ substrate displays another method towards scalability of graphene growth with increased single layer coverage [86]. Li et al. in 2009 demonstrated large-scale graphene synthesis on copper foils by thermal CVD of methane at $1000^{\circ} \mathrm{C}[86]$. The deposition of carbon on copper was described as a high-temperature surface catalyzed process due to the limited solubility of carbon in copper [86]. Additionally, graphene growth on $\mathrm{Cu}$ occurs by segregation of supersaturated carbon and adsorbed carbon on copper surface during the rapid cooling process in CVD copper [86] [87]. Following growth of graphene on $\mathrm{Cu}$ foil, grown graphene was transferred onto another surface through copper etching yielding several chemically unaffected layers of graphene confirmed by Raman spectroscopy and HRTEM [86]. 


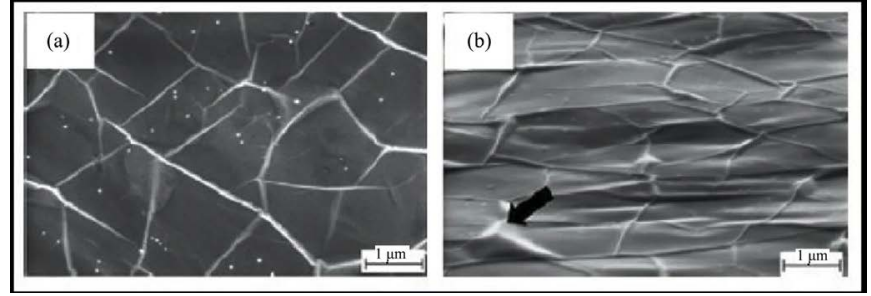

Figure 10. SEM images of graphene synthesis on Ni (111) by CVD method using DC discharge [85].
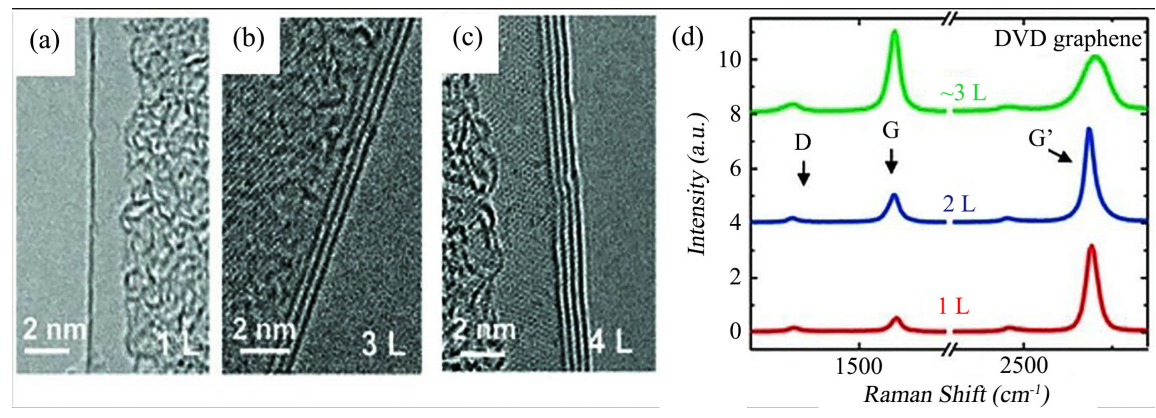

Figure 11. (a)-(c) HRTEM images of one to few layers of graphene grown on Ni using thermal CVD process; (d) Raman spectroscopy displaying the successive graphene layers and intensities [34].

Similarly, Lee et al. [87] developed optimized condition for synthesis of graphene produced by CVD process on $\mathrm{Cu}$ foil. It was observed that high pressure, low hydrogen to methane ratio, with reduced growth time produced graphene layers with improved quality [87]. As shown in Figure 12, there was formation of large $\mathrm{Cu}$ grains due to $\mathrm{Cu}$ grain coalescence during pre-annealing step, formation of copper grain boundary ( $\mathrm{Cu}$ GB) separating the regions of small and big grains, and the presence of graphene folding lines like those obtained by Obraztsov et al. [85] [87].

Furthermore, grown graphene was transferred to a $290 \mathrm{~nm}$-thick $\mathrm{SiO}_{2} / \mathrm{Si}$ substrate. The produced graphene on $\mathrm{Cu}$ substrate was first coated with polymethyl methacrylate (PMMA) on the graphene side to provide strength and serve as protection to avoid graphene damage during the transfer process. In order to etch away the $\mathrm{Cu}$ foil, the PMMA/graphene/Cu structure was placed in $\mathrm{Fe}\left(\mathrm{NO}_{3}\right)_{3}$ solution (Figure 13(b)) with the PMMA side facing up. PMMA/graphene heterostructure was removed from the solution (Figure 13(c)) and rinsed severally in deionized (DI) water to remove residual $\mathrm{Cu}$ etchant solution (Figure 13(d)). The $\mathrm{SiO}_{2} / \mathrm{Si}$ substrate was dipped in DI water (Figure 13(e)) and the PMMA/graphene structure. Through van der Waals forces, the graphene surface adhered to the $\mathrm{SiO}_{2} / \mathrm{Si}$ substrate and the PMMA support was rinsed with solvents (acetone and isopropyl alcohol) (Figure 13(f)). The transferred graphene was distinguishable by the difference in color and contrast compared to the $\mathrm{SiO}_{2} / \mathrm{Si}$ substrate as observed by the naked eye (Figure 13(g)) [87]. Transferred graphene displaced some wrinkles introduced during the transfer process as evidenced by scanning electron microscopy [87]. 

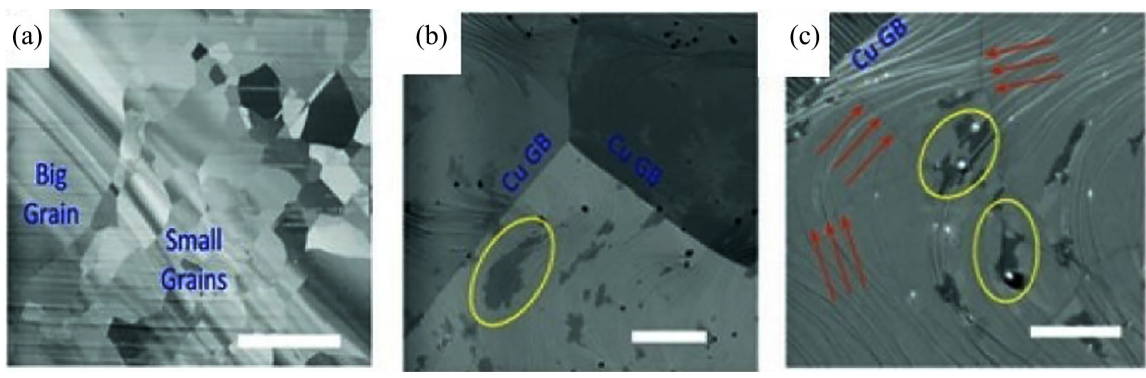

Figure 12. SEM micrographs of graphene via thermal CVD on Cu substrate: (a) Big and small $\mathrm{Cu}$ grains coexisting. Scale bar is $300 \mu \mathrm{m}$; (b) \& (c) Image showing $\mathrm{Cu}$ grain boundary (Cu GB), multilayer graphene (yellow circles), and graphene folding lines (red arrows). Scale bars are $5 \mu \mathrm{m}$ [87].
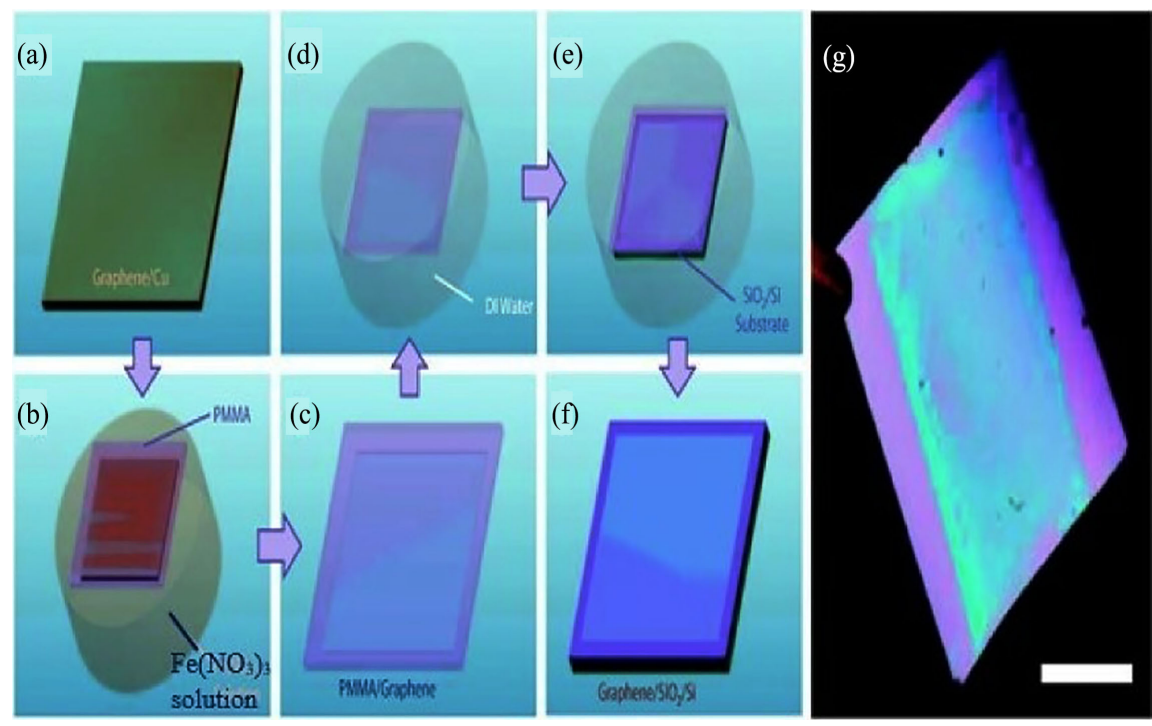

Figure 13. Graphene transfer process (a)-(f) from $\mathrm{Cu}$ substrate to $\mathrm{SiO}_{2} / \mathrm{Si}$ substrate: (a) Graphene synthesized on $\mathrm{Cu}$ foil; (b) Graphene/Cu substrate coated with PMMA in $\mathrm{Fe}\left(\mathrm{NO}_{3}\right)_{3}$ solution; (c) Graphene on PMMA; (d) $\mathrm{Cu}$ etchant solution cleaning using DI water; (e) Contacting $\mathrm{SiO}_{2} / \mathrm{Si}$ substrate with graphene on PMMA in DI water; (f) Final sample by removing PMMA using solvents; (g) Photograph of transferred CVD graphene on $\mathrm{SiO}_{2}$-on-Si substrate. Scale bar is $1 \mathrm{~cm}$ [87].

Numerous reports have shown graphene synthesis on other metal thin films and metal foils [34]. However, graphene growth by CVD method has been mostly done on $\mathrm{Cu}$ [27] [34] and Ni substrates [34]. The problem of producing graphene on $\mathrm{Ni}$ substrate included the time consuming non-self-limiting growth, and the production of large number of wrinkles and folds. Copper substrates have demonstrated more favorable CVD growth of graphene [86].

2) Plasma-Enhanced Chemical Vapor Deposition

This process of graphene production involves chemical reactions of reacting gases inside a vacuum chamber in the presence of plasma resulting in deposits of thin film on the surface of the substrate (Figure 9(b)), thus, the name, plasma-enhanced chemical vapor deposition (PECVD). Sources of plasma in PECVD can include radio frequency (RF), microwave, and inductive coupling (electrical 
currents produced by electromagnetic induction). PECVD process of graphene synthesis is performed at a relatively lower temperature and shorter deposition time than other CVD techniques and as such is more feasible for large scale industrial applications. By controlling the process parameters, catalyst-free growth can be achieved [88]. RF plasma-enhanced chemical vapor deposition has been achieved using substrates such as $\mathrm{Ti}, \mathrm{SiO}_{2}, \mathrm{Si}, \mathrm{Al}_{2} \mathrm{O}_{3}, \mathrm{Mo}, \mathrm{Hf}, \mathrm{Zr}, \mathrm{Nb}, \mathrm{Cr}, \mathrm{W}$, Ta, and 304 stainless steel [5]. This method reduces energy consumption and prevents the formation of unwanted products or amorphous carbon [89].

Thin graphitic layer was first synthesized using PECVD by Obraztsov et al. [90] through DC discharge CVD of a methane and hydrogen mixture. Nanocrystalline graphite growth was observed on silicon wafer, Ni, Mo, and Ni substrates. A thick layer of graphene was produced by this process [90]. Wang et al. [91] deposited graphene on different substrates using PECVD method with RF power of $900 \mathrm{~W}$ while varying methane concentration at different temperatures. Increase in graphene growth rate with increase in temperature and methane concentration was observed [91]. Other studies on graphene synthesis using PECVD were done, such as atmospheric pressure process [92], microwave plasma [93], nitrogen-doped graphene/CNT hybrid structure [94], and many others. PECVD method has been confirmed to produce high-crystalline graphene with high-purity; however, extensive research is ongoing in the production of uniform large-scale and single layer graphene through this technique.

\subsubsection{Other Methods}

Several other ways to produce graphene exists including: arc discharge of graphite [23], electron beam irradiation of PMMA nanofibers [95], and conversion of nanodiamond [96]. Graphene can be synthesized by unzipping of multi-walled carbon nanotubes (MWCNTs) using highly oxidative $\mathrm{KMnO}_{2}$ and concentrated $\mathrm{H}_{2} \mathrm{SO}_{4}$ [38], laser irradiation [38], $\mathrm{Li}$ in liquid ammonia [10], and plasma etching [39] to open up the carbon nanotubes for graphene nanoribbons (GNR) production. Arc discharge methods are also commonly used to synthesis boron- and nitrogen-doped graphene [97] [98]. Arc discharge between carbon electrodes and pyridine or ammonia in the presence of nitrogen has yielded nitrogen-doped graphene sheets [97]. Boron-doped graphene sheet have been synthesized in the presence of hydrogen-diborane vapor mixture or boron-stuffed graphite electrodes [98].

\section{Characterization of Graphene}

Several microscopic and spectroscopic techniques are used to characterize graphene to determine the morphology, structure, quality, presence of defects, and number of layers. The most commonly used characterization techniques are optical microscopy, scanning probe microscopy (SPM), scanning electron microscopy (SEM), high resolution transmission electron microscopy (HRTEM), and Raman spectroscopy. 


\subsection{Optical Microscopy}

Optical microscopy technique is an easy, straightforward, and effective method for non-destructive characterization of graphene. It is primarily used to determine the number of layers in graphene by using the contrast difference between graphene layers and the substrate. Size and shape of the graphene structure is also obtained from this technique. Figure 14(a) shows the optical micrograph with different graphene layers of graphene on $\mathrm{SiO}_{2} / \mathrm{Si}$ substrate [99].

\subsection{Scanning Probe Microscopy}

Scanning probe microscopy (SPM) is a popular technique used to characterize the topography of nanomaterials such as graphene by scanning the sample with a probe. Two SPM commonly used techniques for graphene characterization are atomic force microscopy (AFM) and scanning tunneling microscopy (STM). In the AFM mode, scanning is done in either the contact or noncontact tapping mode of the probe tip with the deflection of the cantilever probe based on the topography of the graphene structure to form $2 \mathrm{D}$ and $3 \mathrm{D}$ images. Figure 14(b) shows the AFM image of mechanically exfoliated graphene flake with atomic-level thickness [100]. STM utilizes tunneling current between the SPM probe and graphene to form similar pattern of the topography of the sample. Figure 14(c) shows high contrast atomic resolution of obtained using STM for graphene hexagonal structure [101].

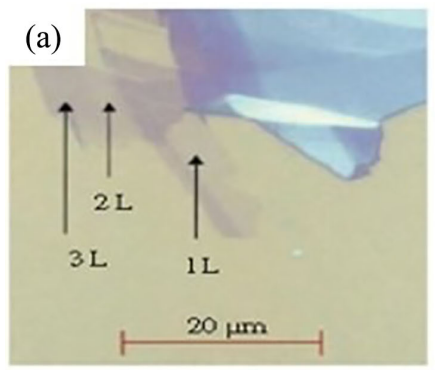

\section{(d)}

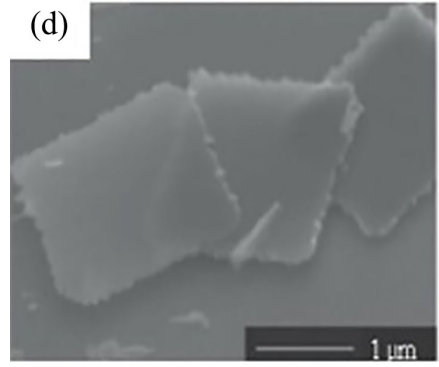

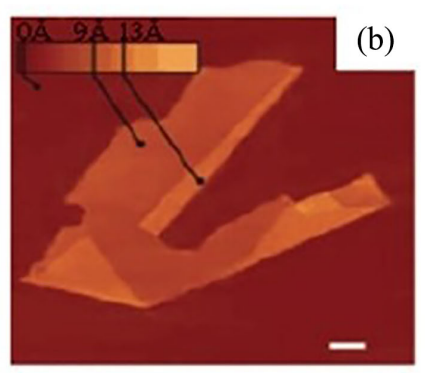

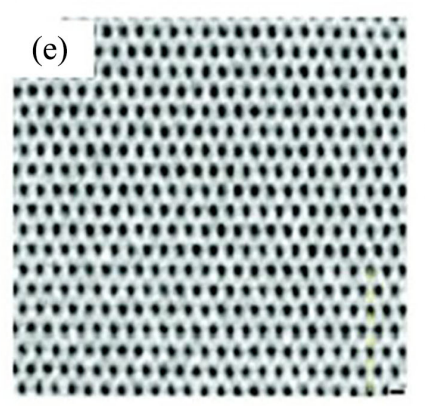

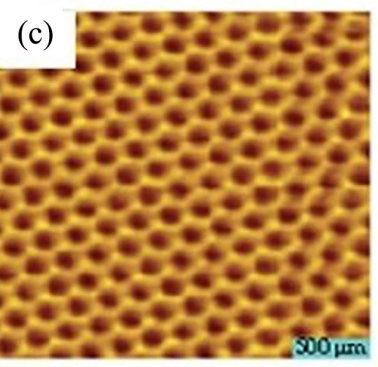

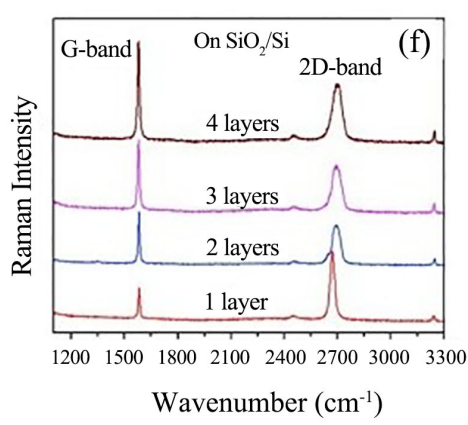

Figure 14. (a) Optical micrograph showing single-(1L), bi-(2L), and trilayer (3L) graphene on $\mathrm{SiO}_{2} / \mathrm{Si}$ substrate [99]; (b) AFM image of mechanically exfoliated graphene (Scale bar is $1 \mu \mathrm{m}$ ) [100]; (c) STM micrograph showing atomic resolution of graphene with hexagonal close-packed lattice structure [101]; (d) SEM micrograph showing exfoliated graphene layers [102]; (e) The hexagonal honeycomb lattice of SLG under HRTEM (Scale bar is $0.2 \mathrm{~nm}$ ) [103]; (f) Raman spectra of one to four layers of graphene on $\mathrm{SiO}_{2} / \mathrm{Si}$ substrate [104]. 


\subsection{Scanning Electron Microscopy}

Scanning electron microscopy (SEM) technique is used to determine surface morphology and number of layers of graphene. This is achieved through focusing a beam of energetic electrons on the sample. Like optical microscopy, there is a contrast difference between graphene layers and the substrate. Figure 14(d) shows a micrograph from SEM for mechanical exfoliated graphene layers [102].

\subsection{High Resolution Transmission Electron Microscopy (HRTEM)}

HRTEM is a very powerful characterization technique for graphene's structural characterizations. Its mode of operation is very similar to the SEM, but in this, the electron beam transmitted through the ultrathin sample. Atomic resolution images can be obtained using the HRTEM. Figure 14(e) shows the atomic arrangement of graphene structure and interfaces using HRTEM [103].

\subsection{Raman Spectroscopy}

Raman spectroscopy is one of the most important technique used today for graphene characterization. It is a nondestructive technique which reveals bonding information. It displays this information as unique fingerprints of graphene in Raman spectra. Information relation to the graphene quality, number of graphene layers, induced strain, presence of defects, and the lattice mismatch can be determined by this technique. Raman spectra of monolayer graphene displays characteristics D-band, G-band, and 2D band at its respective positions of $\sim 1350$ $\mathrm{cm}^{-1}, \sim 1580 \mathrm{~cm}^{-1}$, and $\sim 2690 \mathrm{~cm}^{-1}$ respectively [5]. Figure 14(f) shows the Raman spectra of different layers of graphene on $\mathrm{SiO}_{2} / \mathrm{Si}$ substrate using a laser power of $\sim 532 \mathrm{~nm}[104]$.

Several other characterization techniques for graphene exist, the mostly used methods have been discussed in this paper.

\section{Application}

Since the ground-breaking discovery of the wonder material, graphene, there has been numerous outstanding roles of the material in this century. There are so many areas of application of the novel material. Recent progress in green technology has emerged from the exceptional mechanical, electronics, magnetic, optical, and surface area of functionalized graphene bringing about commercialization and innovative solutions to existing problems such as electronic and photonic applications for ultrahigh-frequency graphene-based devices, anode for li-ion battery [19], sensors [24], nanosized graphene in physics and materials science [21], supercapacitors [23], in ceramics [105], membranes [14], lightweight gas tanks, solar cells, flexible electronics, composite materials, and so many others [105]. Vast areas of research and development continue to open in the area of graphene applications to numerous fields including medicine, electronics, and energy [106] [107] [108]. 


\section{Conclusion}

Discovery of the novel 2D material has revolutionized the nanoelectronics industry by providing an alternative to silicon, which has been used for decades. This contribution has also expanded to bio-medicine, nanorobotics, and energy. However, the issue yet to be resolved is scaling up production of graphene with high quality and uniformity. This is the goal to overcome in the years to come.

\section{Conflicts of Interest}

The authors declare no conflicts of interest regarding the publication of this paper.

\section{References}

[1] Kroto, H.W., Heath, J.R., O’Brien, S.C., Curl, R.F. and Smalley, R.E. (1985) C 60 : Buckminsterfullerene. Nature, 318, 162-163. https://doi.org/10.1038/318162a0

[2] Iijima, S. (1991) Helical Microtubules of Graphitic Carbon. Nature, 354, 56-58. https://doi.org/10.1038/354056a0

[3] Sharon, M. and Sharon, M. (2015) Graphene: An Introduction to the Fundamentals and Industrial Applications. John Wiley \& Sons, Inc., Hoboken.

[4] Novoselov, K.S., et al. (2004) Electric Field in Atomically Thin Carbon Films. Science, 306, 666-669. https://doi.org/10.1126/science.1102896

[5] Das, S., Sudhagar, P., Kang, Y.S. and Choi, W. (2015) Synthesis and Characterization of Graphene. In: Lu, W., Baek, J. and Dai, L., Eds., Carbon Nanomaterials for Advanced Energy Systems, John Wiley \& Sons, Inc., Hoboken, NJ, 85-131. https://doi.org/10.1002/9781118980989.ch3

[6] Choi, W. and Lee, J. (2012) Graphene: Synthesis and Applications. CRC Press, Boca Raton.

[7] Zhu, Y., et al. (2010) Graphene and Graphene Oxide: Synthesis, Properties, and Applications. Advanced Materials, 22, 3906-3924.

[8] Bolotin, K.I., et al. (2008) Ultrahigh Electron Mobility in Suspended Graphene. Solid State Communications, 146, 351-355. https://doi.org/10.1016/j.ssc.2008.02.024

[9] Morozov, S.V., et al. (2008) Giant Intrinsic Carrier Mobilities in Graphene and Its Bilayer. Physical Review Letters, 100, Article ID: 016602.

[10] Lee, C., Wei, X., Kysar, J.W. and Hone, J. (2008) Measurement of the Elastic Properties and Intrinsic Strength of Monolayer Graphene. Science, 321, 385-388. https://doi.org/10.1126/science.1157996

[11] Balandin, A.A., et al. (2008) Superior Thermal Conductivity of Single-Layer Graphene. Nano Letters, 8, 902-907. https://doi.org/10.1021/nl0731872

[12] Moser, J., Barreiro, A. and Bachtold, A. (2007) Current-Induced Cleaning of Graphene. Applied Physics Letters, 91, Article ID: 163513. https://doi.org/10.1063/1.2789673

[13] Kozlov, S.M., Viñes, F. and Görling, A. (2011) Bandgap Engineering of Graphene by Physisorbed Adsorbates. Advanced Materials, 23, 2638-2643. https://doi.org/10.1002/adma.201100171

[14] Bunch, J.S., et al. (2008) Impermeable Atomic Membranes from Graphene Sheets. Nano Letters, 8, 2458-2462. 
[15] Xiong, R., et al. (2016) Ultrarobust Transparent Cellulose Nanocrystal-Graphene Membranes with High Electrical Conductivity. Advanced Materials, 28, 1501-1509. https://doi.org/10.1002/adma.201504438

[16] Eda, G., Fanchini, G. and Chhowalla, M. (2008) Large-Area Ultrathin Films of Reduced Graphene Oxide as a Transparent and Flexible Electronic Material. Nature Nanotechnology, 3, 270-274. https://doi.org/10.1038/nnano.2008.83

[17] Gilje, S., Han, S., Wang, M., Wang, K.L. and Kaner, R.B. (2007) A Chemical Route to Graphene for Device Applications. Nano Letters, 7, 3394-3398.

[18] Li, X., Wang, X., Zhang, L., Lee, S. and Dai, H. (2008) Chemically Derived, Ultrasmooth Graphene Nanoribbon Semiconductors. Science, 319, 1229-1232. https://doi.org/10.1126/science.1150878

[19] Yoo, E., Kim, J., Hosono, E., Zhou, H., Kudo, T. and Honma, I. (2008) Large Reversible Li Storage of Graphene Nanosheet Families for Use in Rechargeable Lithium Ion Batteries. Nano Letters, 8, 2277-2282. https://doi.org/10.1021/nl800957b

[20] Tung, T.T., et al. (2016) Graphene Oxide-Assisted Liquid Phase Exfoliation of Graphite into Graphene for Highly Conductive Film and Electromechanical Sensors. ACS Applied Materials \& Interfaces, 8, 16521-16532. https://doi.org/10.1021/acsami.6b04872

[21] Cai, W., Zhu, Y., Li, X., Piner, R.D. and Ruoff, R.S. (2009) Large Area Few-Layer Graphene/Graphite Films as Transparent Thin Conducting Electrodes. Applied Physics Letters, 95, 123115. https://doi.org/10.1063/1.3220807

[22] Li, X., et al. (2009) Transfer of Large-Area Graphene Films for High-Performance Transparent Conductive Electrodes. Nano Letters, 9, 4359-4363.

[23] Stoller, M.D., Park, S., Zhu, Y., An, J. and Ruoff, R.S. (2008) Graphene-Based Ultracapacitors. Nano Letters, 8, 3498-3502.

[24] Sharma, V., Jain, Y., Kumari, M., Gupta, R., Sharma, S.K. and Sachdev, K. (2017) Synthesis and Characterization of Graphene Oxide (GO) and Reduced Graphene Oxide (rGO) for Gas Sensing Application. Macromolecular Symposia, 376, 1-5. https://doi.org/10.1002/masy.201700006

[25] Liu, Z., Robinson, J.T., Sun, X. and Dai, H. (2008) PEGylated Nanographene Oxide for Delivery of Water-Insoluble Cancer Drugs. Journal of Amercain Chemical Society, 130, 10876-10877. https://doi.org/10.1021/ja803688x

[26] Das, S. and Drucker, J. (2017) Nucleation and Growth of Single Layer Graphene on Electrodeposited $\mathrm{Cu}$ by Cold Wall Chemical Vapor Deposition. Nanotechnology, 28, Article ID: 105601.

[27] Wei, D., Liu, Y., Wang, Y., Zhang, H., Huang, L. and Yu, G. (2009) Synthesis of N-Doped Graphene by Chemical Vapor Deposition and Its Electrical Properties. Nano Letters, 9, 1752-1758. https://doi.org/10.1021/nl803279t

[28] Seyller, T., et al. (2008) Epitaxial Graphene: A New Material. Physica Status Solidi, 245, 1436-1446.

[29] Paredes, J.I., Villar-Rodil, S., Solís-Fernández, P., Martínez-Alonso, A. and Tascón, J.M.D. (2009) Atomic Force and Scanning Tunneling Microscopy Imaging of Graphene Nanosheets Derived from Graphite Oxide. Langmuir, 25, 5957-5968. https://doi.org/10.1021/la804216z

[30] Park, S. and Ruoff, R.S. (2009) Chemical Methods for the Production of Graphenes. Nature Nanotechnology, 4, 217-224.

[31] Allen, M.J., Tung, V.C. and Kaner, R.B. (2010) Honeycomb Carbon: A Review of Graphene. Chemical Reviews, 110, 132-145. 
[32] Viculis, L.M., Mack, J.J. and Kaner, R.B. (2003) A Chemical Route to Carbon Nanoscrolls. Science, 299, 1361. https://doi.org/10.1126/science.1078842

[33] Rollings, E., et al. (2006) Synthesis and Characterization of Atomically Thin Graphite Films on a Silicon Carbide Substrate. Journal of Physics and Chemistry of Solids, 67, 2172-2177. https://doi.org/10.1016/j.jpcs.2006.05.010

[34] Reina, A., et al. (2009) Large Area, Few-Layer Graphene Films on Arbitrary Substrates by Chemical Vapor Deposition. Nano Letters, 9, 30-35.

https://doi.org/10.1021/nl801827v

[35] Liu, N., Luo, F., Wu, H., Liu, Y., Zhang, C. and Chen, J. (2008) One-Step Ionic-Liquid-Assisted Electrochemical Synthesis of Ionic-Liquid-Functionalized Graphene Sheets Directly from Graphite. Advanced Functional Materials, 18, 1518-1525. https://doi.org/10.1002/adfm.200700797

[36] Xin, G., Hwang, W., Kim, N., Cho, S.M. and Chae, H. (2010) A Graphene Sheet Exfoliated with Microwave Irradiation and Interlinked by Carbon Nanotubes for High-Performance Transparent Flexible Electrodes. Nanotechnology, 21, Article ID: 405201. https://doi.org/10.1088/0957-4484/21/40/405201

[37] Jiao, L., Wang, X., Diankov, G., Wang, H. and Dai, H. (2010) Facile Synthesis of High-Quality Graphene Nanoribbons. Nature Nanotechnology, 5, 321-325. https://doi.org/10.1038/nnano.2010.54

[38] Kosynkin, D.V., et al. (2009) Longitudinal Unzipping of Carbon Nanotubes to Form Graphene Nanoribbons. Nature, 458, 872-876. https://doi.org/10.1038/nature07872

[39] Jiao, L., Zhang, L., Wang, X., Diankov, G. and Dai, H. (2009) Narrow Graphene Nanoribbons from Carbon Nanotubes. Nature, 458, 877-880. https://doi.org/10.1038/nature07919

[40] Ebbesen, T.W. and Hiura, H. (1995) Graphene in 3-Dimensions: Towards Graphite origami. Advanced Materials, 7, 582-586. https://doi.org/10.1002/adma.19950070618

[41] Lu, X., Yu, M., Huang, H. and Ruoff, R.S. (1999) Tailoring Graphite with the Goal of Achieving Single Sheets. Nanotechnology, 10, 269-272. https://doi.org/10.1088/0957-4484/10/3/308

[42] Lang, B. (1975) A LEED Study of the Deposition of Carbon on Platinum Crystal Surfaces. Surface Science, 53, 317-329. https://doi.org/10.1016/0039-6028(75)90132-6

[43] Liang, X., et al. (2009) Electrostatic Force Assisted Exfoliation of Prepatterned Few-Layer Graphenes into Device Sites. Nano Letters, 9, 467-472. https://doi.org/10.1021/nl803512z

[44] Ci, L., et al. (2009) Graphene Shape Control by Multistage Cutting and Transfer, Advanced Materials, 21, 4487-4491. https://doi.org/10.1002/adma.200900942

[45] Rao, C.N.R. and Sood, A.K. (2013) Graphene: Synthesis, Properties, and Phenomena. John Wiley \& Sons, Inc., Weinheim, Germany.

[46] Viculis, L.M., Mack, J.J., Mayer, O.M., Hahn, H.T. and Kaner, R.B. (2005) Intercalation and Exfoliation Routes to Graphite Nanoplatelets. Journal of Materials Chemitry, 15, 974-978. https://doi.org/10.1039/b413029d

[47] Bhuyan, M.S.A., Uddin, M.N., Islam, M.M., Bipasha, F.A. and Hossain, S.S. (2016) Synthesis of Graphene. International Nano Letters, 6, 65-83. https://doi.org/10.1007/s40089-015-0176-1

[48] Valles, C., et al. (2008) Solutions of Negatively Charged Graphene Sheets and Rib- 
bons. Journal of the American Chemical Society, 130, 15802-15804.

https://doi.org/10.1021/ja808001a

[49] Kamali, A.R. and Fray, D.J. (2013) Molten Salt Corrosion of Graphite as a Possible Way to Make Carbon Nanostructures. Carbon, 56, 121-131. https://doi.org/10.1016/j.carbon.2012.12.076

[50] Pu, N.-W., Wang, C.-A., Sung, Y., Liu, Y.-M. and Ger, M.-D. (2009) Production of Few-Layer Graphene by Supercritical $\mathrm{CO}_{2}$ Exfoliation of Graphite. Materials Letters, 63, 1987-1989. https://doi.org/10.1016/j.matlet.2009.06.031

[51] Safavi, A., Tohidi, M., Mahyari, F.A. and Shahbaazi, H. (2012) One-Pot Synthesis of Large Scale Graphene Nanosheets from Graphite-Liquid Crystal Composite via Thermal Treatment. Journal of Materials Chemistry, 22, 3825-3831. https://doi.org/10.1039/c2jm13929d

[52] Dhakate, S.R., et al. (2011) An Approach to Produce Single and Double Layer Graphene from Re-Exfoliation of Expanded Graphite. Carbon, 49, 1946-1954. https://doi.org/10.1016/j.carbon.2010.12.068

[53] Staudenmaier, L. (1898) Verfahren zur Darstellung der Graphitsäure. Berichte der Deutschen Chemischen Gesellschaft, 31, 1481-1487. https://doi.org/10.1002/cber.18980310237

[54] Hummers, W.S. and Offeman, R.E. (1958) Preparation of Graphitic Oxide. Journal of the American Chemical Society, 80, 1339. https://doi.org/10.1021/ja01539a017

[55] Eda, G., Lin, Y.-Y., Miller, S., Chen, C.-W., Su, W.-F. and Chhowalla, M. (2008) Transparent and Conducting Electrodes for Organic Electronics from Reduced Graphene Oxide. Applied Physics Letters, 92, Article ID: 233305. https://doi.org/10.1063/1.2937846

[56] Shin, H.-J., et al. (2009) Efficient Reduction of Graphite Oxide by Sodium Borohydride and Its Effect on Electrical Conductance. Advanced Functional Materials, 19, 1987-1992. https://doi.org/10.1002/adfm.200900167

[57] Zhou, X., Zhang, J., Wu, H., Yang, H., Zhang, J. and Guo, S. (2011) Reducing Graphene Oxide via Hydroxylamine: A Simple and Efficient Route to Graphene. The Journal of Physical Chemistry C, 115, 11957-11961. https://doi.org/10.1021/jp202575j

[58] Bourlinos, A.B., Gournis, D., Petridis, D., Szabó, T., Szeri, A. and Dékány, I. (2003) Graphite Oxide: Chemical Reduction to Graphite and Surface Modification with Primary Aliphatic Amines and Amino Acids. Langmuir, 19, 6050-6055. https://doi.org/10.1021/la026525h

[59] Zhang, J., Yang, H., Shen, G., Cheng, P., Zhang, J. and Guo, S. (2010) Reduction of Graphene Oxide via L-Ascorbic Acid. Chemical Communications, 46, 1112-1114. https://doi.org/10.1039/b917705a

[60] Goncalves, G., Marques, P.A.A.P., Granadeiro, C.M., Nogueira, H.I.S., Singh, M.K. and Grácio, J. (2009) Surface Modification of Graphene Nanosheets with Gold Nanoparticles: The Role of Oxygen Moieties at Graphene Surface on Gold Nucleation and Growth. Chemistry of Materials, 21, 4796-4802.

https://doi.org/10.1021/cm901052s

[61] Marcano, D.C., et al., (2010) Improved Synthesis of Graphene Oxide. ACS Nano, 4, 4806-4814.

[62] Zhang, L., Li, Y., Zhang, L., Li, D.W., Karpuzov, D. and Long, Y.T. (2011) Electrocatalytic Oxidation of NADH on Graphene Oxide and Reduced Graphene Oxide Modified Screen-Printed Electrode. International Journal of Electrochemical Science, 
6, 819-829.

[63] Larciprete, R., Fabris, S., Sun, T., Lacovig, P., Baraldi, A. and Lizzit, S. (2011) Dual Path Mechanism in the Thermal Reduction of Graphene Oxide. Journal of the American Chemical Society, 133, 17315-17321. https://doi.org/10.1021/ja205168x

[64] Liao, K.H., Mittal, A., Bose, S., Leighton, C., Mkhoyan, K.A. and MacOsko, C.W. (2011) Aqueous Only Route toward Graphene from Graphite Oxide. ACS Nano, 5, 1253-1258. https://doi.org/10.1021/nn1028967

[65] An, Wong, C.H., Ambrosi, A. and Pumera, M. (2012) Thermally Reduced Graphenes Exhibiting a Close Relationship to Amorphous Carbon. Nanoscale, 4, 4972-4977. https://doi.org/10.1039/c2nr30989k

[66] Viinikanoja, A., Wang, Z., Kauppila, J. and Kvarnström, C. (2012) Electrochemical Reduction of Graphene Oxide and Its in Situ Spectroelectrochemical Characterization. Physical Chemistry Chemical Physics, 14, 14003-14009,. https://doi.org/10.1039/c2cp42253k

[67] Shao, Y., Wang, J., Engelhard, M., Wang, C. and Lin, Y. (2010) Facile and Controllable Electrochemical Reduction of Graphene Oxide and Its Applications. Journal of Materials Chemistry, 20, 743-748. https://doi.org/10.1039/b917975e

[68] Stroyuk, A.L., et al. (2012) Photochemical Reduction of Graphene Oxide in Colloidal Solution. Theoretical and Experimental Chemistry, 48, 2-13.

[69] Krishnamoorthy, K., Veerapandian, M., Kim, G.-S. and Jae Kim, S. (2012) A One Step Hydrothermal Approach for the Improved Synthesis of Graphene Nanosheets. Current Nanoscience, 8, 934-938. https://doi.org/10.2174/157341312803989088

[70] Dai, Z., Wang, K., Li, L. and Zhang, T. (2013) Synthesis of Nitrogen-Doped Graphene with Microwave. International Journal of Electrochemical Science, 8, 9384-9389.

[71] Chua, C.K. and Pumera, M. (2014) Chemical Reduction of Graphene Oxide: A Synthetic Chemistry Viewpoint. Chemical Society Reviews, 43, 291-312. https://doi.org/10.1039/c3cs60303b

[72] Jimenez-Cervantes, E., López-Barroso, J., Martínez-Hernández, A.L. and Velasco-Santos, C. (2016) Graphene-Based Materials Functionalization with Natural Polymeric Biomolecules. Recent Advances in Graphene Research, 257-298. https://doi.org/10.5772/64001

[73] Choucair, M., Thordarson, P. and Stride, J.A. (2009) Gram-Scale Production of Graphene Based on Solvothermal Synthesis and Sonication. Nature Nanotechnolo$g y$, 4, 30-33. https://doi.org/10.1038/nnano.2008.365

[74] Van Bommel, A.J., Crombeen, J.E. and Van Tooren A. (1975) LEED and Auger Electron Observations of the SiC(0001) Surface. Surface Science, 48, 463-472. https://doi.org/10.1016/0039-6028(75)90419-7

[75] Berger, C., et al. (2004) Ultrathin Epitaxial Graphite: 2D Electron Gas Properties and a Route toward Graphene-Based Nanoelectronics. The Journal of Physical Chemistry B, 108, 19912-19916. https://doi.org/10.1021/jp040650f

[76] De Heer, W.A., et al. (2007) Epitaxial Graphene. Solid State Communications, 143, 92-100.

[77] Juang, Z.-Y., et al. (2009) Synthesis of Graphene on Silicon Carbide Substrates at Low Temperature. Carbon, 47, 2026-2031.

[78] Guo, S., Dong, S. and Wang, E. (2010) Three-Dimensional Pt-On-Pd Bimetallic Nanodendrites Supported on Graphene Nanosheet: Facile Synthesis and Used as an Advanced Nanoelectrocatalyst for Methanol Oxidation. ACS Nano, 4, 547-555. 
https://doi.org/10.1021/nn9014483

[79] Sutter, P.W., Flege, J.-I. and Sutter, E.A. (2008) Epitaxial Graphene on Ruthenium. Nature Materials, 7, 406-411. https://doi.org/10.1038/nmat2166

[80] Coraux, J., N'Diaye, A.T., Busse, C. and Michely, T. (2008) Structural Coherency of Graphene on Ir(111). Nano Letters, 8, 565-570. https://doi.org/10.1021/nl0728874

[81] Karu, A.E. and Beer, M. (1966) Pyrolytic Formation of Highly Crystalline Graphite Films. Journal of Applied Physics, 37, 2179-2181. https://doi.org/10.1063/1.1708759

[82] Perdereau, J. and Rhead, G.E. (1971) LEED Studies of Adsorption on Vicinal Copper Surfaces. Surface Science, 24, 555-571. https://doi.org/10.1016/0039-6028(71)90281-0

[83] Eizenberg, M. and Blakely, J.M. (1979) Carbon Monolayer Phase Condensation on $\mathrm{Ni}(111)$. Surface Science, 82, 228-236. https://doi.org/10.1016/0039-6028(79)90330-3

[84] Somani, P.R., Somani, S.P. and Umeno, M. (2006) Planer Nano-Graphenes from Camphor by CVD. Chemical Physics Letters, 430, 56-59. https://doi.org/10.1016/j.cplett.2006.06.081

[85] Obraztsov, A.N., Obraztsova, E.A., Tyurnina, A.V. and Zolotukhin, A.A. (2007) Chemical Vapor Deposition of Thin Graphite Films of Nanometer Thickness. Carbon, 45, 2017-2021. https://doi.org/10.1016/j.carbon.2007.05.028

[86] Li, X., et al. (2009) Large-Area Synthesis of High-Quality and Uniform Graphene Films on Copper Foils. Science, 324, 1312-1314.

[87] Lee, J., Zheng, X., Roberts, R.C. and Feng, P.X.L. (2015) Scanning Electron Microscopy Characterization of Structural Features in Suspended and Non-Suspended Graphene by Customized CVD Growth. Diamond and Related Materials, 54, 64-73. https://doi.org/10.1016/j.diamond.2014.11.012

[88] Shang, N.G., et al. (2008) Catalyst-Free Efficient Growth, Orientation and Biosensing Properties of Multilayer Graphene Nanoflake Films with Sharp Edge Planes. Advanced Functional Materials, 18, 3506-3514. https://doi.org/10.1002/adfm.200800951

[89] Zhu, M., et al. (2007) A Mechanism for Carbon Nanosheet Formation. Carbon, 45, 2229-2234.

[90] Obraztsov, A.N., Zolotukhin, A.A., Ustinov, A.O., Volkov, A.P., Svirko, Y. and Jefimovs, K. (2003) DC Discharge Plasma Studies for Nanostructured Carbon CVD. Diamond and Related Materials, 12, 917-920. https://doi.org/10.1016/s0925-9635(02)00338-2

[91] Wang, J.J., et al. (2004) Free-Standing Subnanometer Graphite Sheets. Applied Physics Letters, 85, 1265-1267.

[92] Jăsek, O., Synek, P., Zajíčkováa, L., Elíăs, M. and Kudrle, V. (2010) Synthesis of carbon Nanostructures by Plasma Enhanced Chemical Vapour Deposition at Atmospheric Pressure. Journal of Electrical Engineering, 61, 311-313. https://doi.org/10.2478/v10187-011-0049-9

[93] Yuan, G.D., et al. (2009) Graphene Sheets via Microwave Chemical Vapor Deposition. Chemical Physics Letters, 467, 361-364.

[94] Lee, D.H., Lee, J.A., Lee, W.J., Choi, D.S., Lee, W.J. and Kim, S.O. (2010) Facile Fabrication and Field Emission of Metal-Particle-Decorated Vertical N-Doped Carbon Nanotube/Graphene Hybrid Films. The Journal of Physical Chemistry C, 114, 21184-21189. https://doi.org/10.1021/jp1077714

[95] Subrahmanyam, K.S., Panchakarla, L.S., Govindaraj, A. and Rao, C.N.R. (2009) 
Simple Method of Preparing Graphene Flakes by an Arc-Discharge Method. The Journal of Physical Chemistry C, 113, 4257-4259. https://doi.org/10.1021/jp900791y

[96] Subrahmanyam, K.S., Vivekchand, S.R.C., Govindaraj, A. and Rao, C.N.R. (2008) A Study of Graphenes Prepared by Different Methods: Characterization, Properties and Solubilization. Journal of Materials Chemistry, 18, 1517-1523. https://doi.org/10.1039/b716536f

[97] Panchakarla, L.S., et al. (2009) Synthesis, Structure, and Properties of Boron- and Nitrogen-Doped Graphene. Advanced Materials, 21, 4726-4730.

[98] Ci, L., et al. (2010) Atomic Layers of Hybridized Boron Nitride and Graphene Domains. Nature Materials, 9, 430-435

[99] Park, J.S., Reina, A., Saito, R., Kong, J., Dresselhaus, G. and Dresselhaus, M.S. (2009) G' Band Raman Spectra of Single, Double and Triple Layer Graphene. Carbon, 47, 1303-1310.

[100] Novoselov, K.S., et al. (2005) Two-Dimensional Atomic Crystals. Proceedings of the National Academy of Sciences, 102, 10451-10453.

[101] Luican, A., Li, G. and Andrei, E.Y. (2009) Scanning Tunneling Microscopy and Spectroscopy of Graphene Layers on Graphite. Solid State Communications, 149, 1151-1156. https://doi.org/10.1016/j.ssc.2009.02.059

[102] Zhang, Y.J., Small, P., Pontius, W.V. and Kim, P. (2005) Fabrication and Electric-Field-Dependent Transport Measurements of Mesoscopic Graphite Devices, Applied Physics Letters, 86, Article ID: 073104. https://doi.org/10.1063/1.1862334

[103] Huang, P.Y., et al. (2011) Grains and Grain Boundaries in Single-Layer Graphene Atomic Patchwork Quilts. Nature, 469, 389-392.

[104] Wang, Y.Y., et al. (2008) Raman Studies of Monolayer Graphene: The Substrate Effect. The Journal of Physical Chemistry C, 112, 10637-10640.

[105] Chandrasekhar, P. (2018) Conducting Polymers, Fundamentals and Applications. Cham: Springer International Publishing, Boston.

[106] Ding, X., Liu, H. and Fan, Y. (2015) Graphene-Based Materials in Regenerative Medicine. Advanced Healthcare Materials, 4, 1451-1468.

[107] Torrisi, F., et al. (2012) Inkjet-Printed Graphene Electronics. ACS Nano, 6, 2992-3006.

[108] Sun, Y., Wu, Q. and Shi, G. (2011) Graphene Based New Energy Materials. Energy and Environmental Science, 4, 1113-1132. 